\title{
INVESTIGATION OF THE PROGRESS IN THE WOMEN WITH GESTATIONAL DIABETES MELLITUS POSTPARTUM
}

Nhu Phan Thi To ${ }^{1}$, Vinh Hoang Trung ${ }^{2}$

1. Ha Noi University of Pharmacy

2. Military Medical Univerisy

DOI: $10.47122 / v j d e .2020 .40 .8$

\begin{abstract}
Aims: Our aim was to evaluate the uptake of postpartum screening, the prevalence and the risk factors for glucose intolerance in women with a recent history of gestational diabetes mellitus (GDM). Methods: All women with a history of GDM are advised to undergo a $75 \mathrm{~g}$ oral glucose tolerance test (OGTT) around 6 - 12 weeks postpartum. Indices of insulin sensitivity (the Matsuda index and the reciprocal of the homeostasis model assessment of insulin resistance, HOMA-IR) and an index of beta-cell function, the Insulin Secretion-Sensitivity Index-2 (ISSI-2) were calculated based on the OGTT postpartum. Multivariable logistic regression was used to some factors. Results: Of all women (135) who received an OGTT postpartum, $42.2 \% \quad$ (57) had glucose intolerance (11.8\% impaired fasting glucose, $24.4 \%$ impaired glucose tolerance and $6.0 \%$ both impaired fasting and impaired glucose tolerance) and $1.5 \%$ (2) had overt diabetes. Compared to women with a normal OGTT postpartum, women with glucose intolerance and diabetes were older $(32.5 \pm 4.3$ vs. $30.8 \pm$ 4.8 years, $\mathrm{p}=0.049$ ), were more often obese $(34.5 \%$ vs. $17.3 \%, p=0.023)$. In the multivariable logistic regression, an EM background $[\mathrm{OR}=2.76(1.15-6.62), \mathrm{p}=$ 0.023 ] and the HbA1c level at the time of the OGTT in pregnancy [OR $=4.78(1.19-$ 19.20), $\mathrm{p}=0.028$ ] remained significant predictors for glucose intolerance postpartum. Women with glucose intolerance and diabetes postpartum had a similar insulin sensitivity [Matsuda index $0.656(0.386$ - 1.224) vs. $0.778(0.532-1.067), \mathrm{p}=0.709$; HOMA-IR $0.004(0.002-0.009)$ vs. $0.064(0.003$ $0.007), \mathrm{p}=0.384]$ but a lower beta-cell function compared to women with a normal
\end{abstract}

OGTT postpartum, remaining significant after adjustment for confounders [ISSI-2 1.6 (1.2 $2.1)$ vs. $1.9(1.7-2.4), \mathrm{p}=0.002]$. Conclusions: Glucose intolerance is very frequent in early postpartum in women with GDM these women have an impaired betacell function. Nearly one third of women did not attend the scheduled OGTT postpartum and these women have an adverse risk profile. More efforts are needed to engage and stimulate women with GDM to attend the postpartum OGTT.

Keywords: Gestational Diabetes, Prediabetes, Oral glucose tolerance test, Impaired fasting glucose, Impaired glucose tolerance, Diabetes, Insulin resistance.

Main correspondence: Phan Thi To Nhu

Submission date: $5^{\text {th }}$ May 2020

Revised date: $15^{\text {th }}$ May 2020

Acceptance date: $26^{\text {th }}$ June 2020

Email: hieunhu_1983@yahoo.com

\section{INTRODUCTION}

Changes in pregnant women related to carbohydrate metabolism through changes in hormones, especially during pregnancy, cause changes in concentration and peripheral insulin resistance, leading to increased glucose. All of the above changes appear to maintain normal blood glucose during pregnancy [1]. Gestational diabetes mellitus is a common metabolic disease in pregnant women [2]. Long-term follow-up of these women is an increased risk of type 2 diabetes mellitus (T2DM) and cardiovascular complications at later stage [3].

There are several risk factors for increasing the progression to T2DM, including overweight, obesity, history of family with T2DM, history of hypertension, prediabetes, multipareous. Women with 
glucose intolerance or diabetes should be follow up and appropriate interventions to reverse or delay the progession of previously existing disorders. During the 3 months postpartum in subjects with glucose intolerance during pregnancy should perform diagnostic tests based on ADA recommendations. The study aimed to evaluate glucose tolerance for 6 - 12 weeks postpartum and the association with some factors in women with a history of gestational diabetes mellitus.

\section{METHODS}

\section{Subjects and design}

We designed a prospective combining retrospective observational study of women who had a history of GDM diagnosed at the Obstetrics and Gynecology Hospital in $\mathrm{Ha}$ Noi, from 01-01-2019 till 31-12-2019.

Selection criteria: The women with a single fetus diagnosed with GDM at $24^{\text {th }}-28^{\text {th }}$ week of gestation, had a period of $6-12$ weeks postpartum, did not use insulin for 12 weeks postpartum. The patients agreed to participate in the study.

Exclution criteria: The women had diabetes before pregnancy; kidney, liver, cardiac and chronic systemic inflammatory and infectious diseases; endocrine disorders; use of drugs that might affect blood glucose and insulin levels. The patients did not agree to participate in the study.

The study was conducted on a total of 135 patients.

\section{Clinical and biochemical analysis}

Outcomes were obtained from review of the electronic database. Maternal characteristics recorded were age, weight, body mass index (BMI) at first prenatal visit and at delivery, multiparous, hypertension and glucose intolerance before pregnancy, family history of diabetes, history of GDM, $\mathrm{HbA}_{1} \mathrm{c}$, the glucose values and the insulin values based on the $75 \mathrm{~g}$ OGTT during pregnancy $(0$ $\min -60 \mathrm{~min}-120 \mathrm{~min}$ ) and the gestational age at the start of insulin.

All women who have had GDM at 6-12 weeks postpartum received a $2 \mathrm{~h} 75 \mathrm{~g}$ OGTT. Other data that were recorded are the glucose values and the insulin values based on the $75 \mathrm{~g}$ OGTT postpartum.

\section{Study Assessments}

Diagnose diabetes according the ADA 2019: Fasting plasma glucose (FPG) $\geq 7,0$ $\mathrm{mmol} / \mathrm{l}$ or 2 hours plasma glucose $(\mathrm{PG}) \geq$ $11,1 \mathrm{mmol} / 1$ during OGTT or $\mathrm{A}_{1} \mathrm{c} \geq 6,5 \%$ or a random $P G \geq 11,1 \mathrm{mmol} / 1$ in a patient with classic symptoms of hyperglycemia crisis.

Diagnose prediabetes according the ADA 2019: IFG $5.6-6.9 \mathrm{mmol} / \mathrm{l}$ or 2 hours IGT $7.8-11.0 \mathrm{mmol} / \mathrm{l}$ during 75 -g OGTT or $\mathrm{A}_{1} \mathrm{C}$ $5.7-6.4 \%$.

The BMI was calculated and classificated according the WHO (2000) recommendation for Asia-Pacific: overweight (BMI $\geq 23$ $\mathrm{kg} / \mathrm{m}^{2}$ ), obesity BMI $\geq 25 \mathrm{~kg} / \mathrm{m}^{2}$ ).

Insulin resistance and function of beta-cell was calculated using the Homestasis Model Assement for insulin resistance (HOMA-IR) index, Matsuda index and Insulin SecretionSensitivity Index-2 (ISSI-2).

\section{Statistical analysis}

Statistical analyses were performed by using the SPSS, version 22.0. Data was reported as mean \pm standard deviation (SD) or median/ interquartile range, according with the normal distribution status. For parametrically distributed data, Student's ttest was used in comparisons of the means of tưo groups. For non-parametrically distributed data, the Mann-Whitney $U$ test was used.

Correlations between data were investigated using Pearson's correlation test. In multiple variable examinations, the linear regression model was used for continuous variable, whereas the logistic regression model was used for categorical variables. The level of statistical significance for all test was set at $\mathrm{p}<0.05$. 


\section{RESULTS}

Table 3.1. Patients distribution according to glucose tolerance $(n=135)$

\begin{tabular}{|l|l|c|c|}
\hline \multicolumn{2}{|l|}{} & Number (n) & Ratio (\%) \\
\hline Normal & IFG & 76 & 56.3 \\
\cline { 2 - 4 } & IGT & 16 & 11.8 \\
\cline { 2 - 4 } $\begin{array}{l}\text { Glucose intolerance/ } \\
\text { Diabetes }\end{array}$ & IFG + IGT & 33 & 24.4 \\
\cline { 2 - 4 } & ĐTĐ & 8 & 6.0 \\
\hline
\end{tabular}

Comments: Of all women (135) who received an OGTT postpartum, 42.2\% (57) had glucose intolerance (11.8\% impaired fasting glucose, $24.4 \%$ impaired glucose tolerance and $6.0 \%$ both impaired fasting and impaired glucose tolerance) and $1.5 \%$ (2) had overt diabetes.

Table 3.2. Comparison of the characteristics between women with a normal OGTT and women with gluocse intolerance/ diabetes postpartum

\begin{tabular}{|c|c|c|c|}
\hline & $\begin{array}{l}\text { Normal } \\
(n=76)\end{array}$ & $\begin{array}{c}\text { Gluocse } \\
\text { intolerance/ } \\
\text { diabetes } \\
(\mathbf{n}=\mathbf{5 9})\end{array}$ & p value \\
\hline Age mean years & $30.8 \pm 4.8$ & $32.5 \pm 4.3$ & 0.049 \\
\hline BMI at first prenatal visit & $25.4 \pm 5.5$ & $27.2 \pm 5.6$ & $\mathbf{0 . 0 3 5}$ \\
\hline Weight gain & $15.0 \pm 1.7$ & $15.4 \pm 2.0$ & 0.658 \\
\hline$\%$ history of family with T2DM & 11.8 & 11.9 & 0.084 \\
\hline$\%$ history of hypertension & 6.6 & 15.3 & 0.101 \\
\hline$\%$ multipareous & 60.5 & 59.3 & 0.887 \\
\hline Week at diagnosis of GDM (median) & $22.5(24.2-26.2)$ & $25.0(24.0-26.7)$ & 0.671 \\
\hline Median fasting on $75 \mathrm{~g}$ OGTT $(\mathrm{mmol} / \mathrm{l})$ & $8.5(8.02-9.7)$ & $9.4(8.55-10.44)$ & 0.059 \\
\hline $\begin{array}{l}\% \text { glucose abnormal on OGTT during } \\
\text { pregnancy }\end{array}$ & 37.3 & 55.6 & 0.04 \\
\hline $\begin{array}{l}\% 1 \mathrm{~h} \text { glucose abnormal on OGTT during } \\
\text { pregnancy }\end{array}$ & 48.0 & 40.7 & 0.414 \\
\hline $\begin{array}{l}\% 2 \mathrm{~h} \text { glucose abnormal on OGTT during } \\
\text { pregnancy }\end{array}$ & 62.7 & 53.7 & 0.307 \\
\hline $\begin{array}{l}\% \geq 2 \text { values abnormal on OGTT during } \\
\text { pregnancy }\end{array}$ & 40.0 & 40.7 & 0.933 \\
\hline $\begin{array}{l}\% \geq 3 \text { values abnormal on OGTT during } \\
\text { pregnancy }\end{array}$ & 9.3 & 9.3 & 0.989 \\
\hline $\begin{array}{l}\mathrm{HbA}_{1} \mathrm{c} \% \text { (median) on OGTT during } \\
\text { pregnancy }\end{array}$ & $5.0(4.8-5.2)$ & $5.1(5.0-5.4)$ & 0.001 \\
\hline$\%$ increased insulin & 18.7 & 28.8 & 0.164 \\
\hline $\begin{array}{l}\text { Weeks start insulin (median) during } \\
\text { pregnancy }\end{array}$ & $29.2(27.7-31.0)$ & $28.0(50.0-30.2)$ & 0.316 \\
\hline
\end{tabular}


Comments: Compared to women with a normal OGTT postpartum, women with glucose intolerance/ diabetes were more often BMI at first prenatal visit, were more often glucose abnormal on OGTT during pregnancy, had a higher age, had a higher HbA1c index on OGTT during pregnancy.

Table 3.3. Independent prognostic values of glucose intolerance postpartum

\begin{tabular}{|l|c|c|c|c|}
\hline & $\begin{array}{c}\text { Degrees of } \\
\text { freedom }\end{array}$ & SE & $\begin{array}{c}\text { OR } \\
(\mathbf{9 5 \%} \text { CI) }\end{array}$ & $\begin{array}{c}\text { p } \\
\text { value }\end{array}$ \\
\hline Age & 1 & 0.43 & $1.07(0.98-1.16)$ & 0.123 \\
\hline BMI & 1 & 0.036 & $1,04(0.97-1.12)$ & 0.218 \\
\hline History of family with T2DM & 1 & 0.61 & $0,91(0.28-2.99)$ & 0.877 \\
\hline History of hypertension & 1 & 0.65 & $2,35(0.66-8.42)$ & 0.188 \\
\hline Multipareous & 1 & 0.44 & $0,53(0.22-1.25)$ & 0.149 \\
\hline EM background & 1 & 0.21 & $2.76(1.15-6.62)$ & $\mathbf{0 . 0 2 3}$ \\
\hline Week at diagnosis of GDM & 1 & 0.20 & $0.85(0.57-1.27)$ & 0.426 \\
\hline Fasting on OGTT during pregnancy & 1 & 0.01 & $1.01(0.98-1.03)$ & 0.525 \\
\hline $\begin{array}{l}\text { Fasting abnormal on OGTT during } \\
\text { pregnancy }\end{array}$ & 1 & 0.02 & $1.03(0.98-1.07)$ & 0.240 \\
\hline $\begin{array}{l}\text { 1h glucose value on OGTT during } \\
\text { pregnancy }\end{array}$ & 1 & 0.01 & $1.00(0.99-1.01)$ & 0.559 \\
\hline $\begin{array}{l}\text { 2h glucose value on OGTT during } \\
\text { pregnancy }\end{array}$ & 1 & 0.01 & $0.99(0.98-1.00)$ & 0.125 \\
\hline$\geq 2$ values abnormal on OGTT & 1 & 0.40 & $0.71(0.32-1.57)$ & 0.397 \\
\hline$\geq 3$ values abnormal on OGTT & 1 & 0.68 & $0.64(0.17-2.44)$ & 0.518 \\
\hline HbA1c on OGTT during pregnancy & 1 & 0.71 & $4.78(1.19-1.92)$ & $\mathbf{0 . 0 2 8}$ \\
\hline Increased insulin & 1 & 0.47 & $1.16(0.46-2.93)$ & 0.753 \\
\hline Weeks start insulin during pregnancy & 1 & 0.11 & $0.97(0.78-1.21)$ & 0.801 \\
\hline
\end{tabular}

Comments: EM background and HbAlc on OGTT during pregnancy is an independent prognostic factor for glucose intolerance postpartum.

Table 3.4. Comparison of the beta-cell function and insulin sensitivity between women with a normal OGTT and women with gluocse intolerance/ diabetes postpartum

\begin{tabular}{|c|c|c|c|c|}
\hline & $\begin{array}{c}\text { Normal } \\
(\mathbf{n}=\mathbf{7 6})\end{array}$ & $\begin{array}{c}\text { Gluocse intolerance/ } \\
\text { diabetes } \\
\mathbf{( n = 5 9 )}\end{array}$ & p value & $\begin{array}{c}\text { Adjusted } \\
\mathbf{p} \text { value }\end{array}$ \\
\hline ISSI-2 & $1.9(1.7-2.4)$ & $1.6(1.2-2.1)$ & $<\mathbf{0 . 0 0 0 1}$ & 0.002 \\
\hline $\begin{array}{c}\text { Matsuda } \\
\text { Index }\end{array}$ & $0.778(0.532-1.067)$ & $0.656(0.386-1.224)$ & 0.279 & 0.709 \\
\hline HOMA-IR & $0.004(0.003-0.007)$ & $0.004(0.002-0.009)$ & 0.699 & 0.384 \\
\hline
\end{tabular}

Comments: The ISSI-2 in women with gluocse intolerance/ diabetes postpartum decreased statistically significant compared to the women with a normal OGTT $(\mathrm{p}<0.0001)$.

Table 3.5. Comparison of the characteristics between women with an impaired fasting glucose (IFG) and women with an impaired glucose tolerance (IGT) postpartum

\begin{tabular}{|l|c|c|c|}
\hline & IFG $(\mathbf{n}=\mathbf{1 6})$ & IGT $(\mathbf{n}=\mathbf{3 3})$ & p value \\
\hline Age mean years & $32.0 \pm 5.3$ & $33.5 \pm 3.6$ & 0.255 \\
\hline BMI at first prenatal visit & $31.3 \pm 4.4$ & $25.2 \pm 4.8$ & $<\mathbf{0 . 0 0 0 1}$ \\
\hline
\end{tabular}




\begin{tabular}{|c|c|c|c|}
\hline$\%$ history of family with T2DM & 18.8 & 12.1 & 0.659 \\
\hline$\%$ history of hypertension & 12.5 & 9.1 & 0.712 \\
\hline$\%$ multipareous & 50.0 & 60.6 & 0.482 \\
\hline Week at diagnosis of GDM (median) & $25.5(24.6-27.1)$ & $\begin{array}{l}25.0(24.0- \\
27.5)\end{array}$ & 0.667 \\
\hline Median fasting on $75 \mathrm{~g}$ OGTT (mmol/1) & $8.2(6.7-9.1)$ & $9.5(8.7-10.7)$ & 0.016 \\
\hline $\begin{array}{l}\% \text { glucose abnormal on OGTT during } \\
\text { pregnancy }\end{array}$ & 80.0 & 43.3 & 0.02 \\
\hline $\begin{array}{l}\% 1 \mathrm{~h} \text { glucose abnormal on OGTT } \\
\text { during pregnancy }\end{array}$ & 40.0 & 40.0 & 1.00 \\
\hline $\begin{array}{l}\% 2 \mathrm{~h} \text { glucose abnormal on OGTT } \\
\text { during pregnancy }\end{array}$ & 33.3 & 66.7 & 0.034 \\
\hline $\begin{array}{l}\% \geq 2 \text { values abnormal on OGTT } \\
\text { during pregnancy }\end{array}$ & 40.0 & 46.7 & 0.671 \\
\hline $\begin{array}{l}\% \geq 3 \text { values abnormal on OGTT } \\
\text { during pregnancy }\end{array}$ & 13.3 & 3.3 & 0.205 \\
\hline $\begin{array}{l}\text { Median fasting on OGTT }(\mathrm{mmol} / \mathrm{l}) \\
\text { during pregnancy }\end{array}$ & $5.3(5.2-5.6)$ & $5.04(4.5-5.1)$ & 0.012 \\
\hline $\begin{array}{l}1 \mathrm{~h} \text { glucose value on OGTT during } \\
\text { pregnancy }\end{array}$ & $8.4(7.7-11.4)$ & $9.6(9.2-10.9)$ & 0.306 \\
\hline $\begin{array}{l}2 \mathrm{~h} \text { glucose value on OGTT during } \\
\text { pregnancy }\end{array}$ & $6.4(6.1-8.8)$ & $8.8(8.0-9.3)$ & 0.006 \\
\hline$\%$ Increased insulin & 31.3 & 21.2 & 0.444 \\
\hline Weeks start insulin during pregnancy & $28.0(20.5-32.5)$ & $29.0(27.0-31.0)$ & 0.530 \\
\hline
\end{tabular}

Comments: In IFG subjects: prenatal BMI, abnormal glucose tolerance and blood glucose value on OGTT during pregnancy were significantly higher than that of IGT subjects. In contrast to the average glucose value and $2 \mathrm{~h}$ glucose abnormal on OGTT during pregnancy are lower than that of IGT subjects.

Table 3.6. Comparison of the beta-cell function and insulin sensitivity between women with an impaired fasting glucose (IFG) and women with an impaired glucose tolerance (IGT) postpartum

\begin{tabular}{|l|c|c|c|c|}
\hline & IFG $(\mathbf{n}=\mathbf{1 6})$ & IGT $(\mathbf{n}=\mathbf{3 3})$ & p value & $\begin{array}{c}\text { Adjusted } \\
\text { p value }\end{array}$ \\
\hline ISSI-2 & $1.7(1.1-2.2)$ & $1.6(1.3-2.1)$ & 0.890 & 0.610 \\
\hline Matsuda Index & $0.441(0.365-1.527)$ & $0.696(0.414-1.160)$ & 0.396 & 0.977 \\
\hline HOMA-IR & $0.003(0.002-0.007)$ & $0.005(0.002-0.009)$ & 0.209 & 0.737 \\
\hline
\end{tabular}

Comments: The values of ISSI-2, Matsuda index, HOMA-IR between two subgroups are not statistically significantly.

\section{DISCUSSION}

Gestational diabetes mellitus develops in a variety of ways, which can change the status or be permeable. Most cases can return to normal due to hormone-endocrine disorders restored. A few cases change to T2DM or prediabetes (IFG and/ or IGT) [5]. All of women who received an OGTT at 6-12 weeks postpartum, $1.5 \%(2 / 135)$ had diabetes,
$42.2 \%(57 / 135)$ had glucose intolerance of which $24.4 \%$ (33/135) had IGT, $11.8 \%$ $(16 / 135)$ had IFG, and 6\% (8/135) had IGT/ IFG combined. Among the study subjects, $23.2 \%$ had to use insulin to treat diabetes. This ratio is similar to the cohort study of Duran A et al [6]. Evaluation based on HbAlc alone or in combination with glucose tolerance in women with GDM will give a 
contrast to the rate of HbAlc and glucose sensitivity when performing a combination therapy ranging from $83 \%$ to $90 \%$ [7].

Among the risk factors forr glucose intolerance postpartum, it was found that overweight and obesity were significant. Accordingly, IFG subjects showed higher obesity than IGT at the time on OGTT during pregnancy. Some authors suggest that earlypostpartum IFG subjects had lower insulin sensitivity than IGT. However, the survey results did not find any difference in beta-cell function index and insulin sensitivity between the two subgroups. It is also possible that due to the small number of subjects and criteria of WHO 2013 will reduce the incidence.

The majority of authors recognize the role of risk factors for glucose intolerance in early postpartum women. The common factors including maternal age, weight gain before pregnancy, GDM early onset, treated with insulin during pregnancy [8]. In this study, it was found that EM background and HbA1c on OGTT during pregnancy was an independent prognostic factor for glucose intolerance, and other factors were not found to have a clear role. It can be said that EM background and $\mathrm{HbAlc}$ index are factors that have prognostic value of glucose tolerance within this topic.

\section{CONCLUSIONS}

Survey of 135 women who had a history of GDM at 6 - 12 weeks postpartum found:

$+42.2 \%$ had glucose intolerance, of which IGT had the highest rate $24.4 \%$, followed by IFG $11.8 \%$ and $6 \%$ combined both conditions.

$+1,5 \%$ had diabetes.

+ Mean age, prenatal obesity rate, abnormal glucose tolerance during pregnancy, HbAlc on OGGT during pregnancy in subjects with glucose intolerance/diabetes was significantly higher than subjects with normal glucose tolerance.

+ EM background and HbA1c on OGGT during pregnancy are independent prognostic factors that cause glucose intolerance.
+ Function of beta-cell (ISSI-2) in subjects with glucose intolerance was significantly lower than subjects with normal glucose tolerance $(\mathrm{p}<0,0001)$.

+ There was no significant difference between beta-cell function and insulin resistance in IFG and IGT subgroups.

+ In IFG subjects: prenatal BMI, abnormal glucose tolerance and blood glucose value on OGTT during pregnancy were significantly higher than that of IGT subjects. In contrast to the average glucose value and $2 \mathrm{~h}$ glucose abnormal on OGTT during pregnancy are lower than that of IGT subjects.

+ Glucose intolerance in women with a history of GDM occurs in the early postpartum period with a manifestation of impaired insulin secretion function of betacell. The OGTT should be performed for all postpartum subjects.

\section{REFERENCES}

1. American Diabetes Association. Diagnosis and classification of diabetes mellitus. Diabetes Care 2009; 32 (suppl 1):S62-S67.

2. Crowther CA, Hiller JE, Moss JR, McPhee AJ, Jeffries W, Robinson JS. Australian Carbohydrate Intolerance study in Pregnancy Women (ACHOIS) Trial Group. Effect of treatment of gestational diabetes mellitus on pregnancy outcomes. N Engl J Med 2005: 352;2477-2486.

3. Landon MB, Spong CY, Thom E, Carpenter M, Ramin SM, Casey B, et al; Eunice Kennedy Shriver National Institute of Child Health and Human Development Maternal-Fetal Medicine Units Network. A multicenter, randomized trial of treatment for mild gestational diabetes. N Engl J Med 2009; 361:1339- 1348.

4. International Association of Diabetes and Pregnancy Study Groups Consensus Panel. International association of diabetes and pregnancy study groups 
recommendations on the diagnostic and classification of hyperglycemia in pregnancy. Diabetes Care 2010; 33:676682.

5. Metzger BE, Buchanan TA, Coustan DR, de Leiva A, Dunger DB, Hadden DR, et al. Summary and recommendations of the Fifth International Workshop-Conference on Gestational Diabetes Mellitus. Diabetes Care 2007; 30 (suppl 2):S251S260.

6. Duran A, Sáenz S, Rorrejón MJ, Bordiú E, Del Valle L, Galindo $M$, et al. Introduction of IADPSG criteria for the screening and diagnosis of gestational diabetes mellitus results in improved pregnancy outcomes at a lower cost in a large cohort of pregnant women: the St Carlos gestational diabetes study. Diabetes Care 2014; 37:2442-2450.

7. Picón MJ, Murri M, Muñoz A, Fernandez-Garcia JC, Gomez-Huelgas $\mathrm{R}$, Tinahones FJ. Hemoglobin Alc versus oral glucose tolerance test in postpartum diabetes screening. Diabetes Care 2012; 35: 1648-1653.

8. Leuridan L, Wens J, Devlieger R, Verhaeghe J, Mathieu C, Benhalima K. Glucose intolerance in early postpartum in women with gestational diabetes: Who is at increased risk? Primary Care Diabetes 2015; 9, 244-252. 